\title{
THE SEMIOTIC WORK OF THE HANDS IN SCIENTIFIC ENQUIRY
}

\author{
Mona Sakr, Carey Jewitt \& Sara Price* \\ Institute of Education, London
}

\begin{abstract}
This paper takes a multimodal approach to analyzing embodied interaction and discourses of scientific investigation using an interactive tangible tabletop. It argues that embodied forms of interaction are central to science inquiry. More specifically, the paper examines the role of hand actions in the development of descriptions and explanations of scientific phenomena in tangible digital learning environments. It reports an observational study of primary school students aged 10-11 years conducting scientific investigations via an interactive tangible tabletop. Through the systematic tracking and analysis of hand action in line with phases of scientific inquiry the paper maps, critiques and extends previous research, notably Roth's concept of a 'developmental trajectory', to develop a 'taxonomy' of hand actions for scientific inquiry in tangible digital learning environments. The paper concludes by presenting an alternative model through which to understand the semiotic role of the hands in scientific inquiry, one in which different hand actions do not follow a simple developmental sequence, but instead fulfill different functions across the inquiry process.
\end{abstract}




\section{Introduction}

In the context of emerging digital technologies, the role of the body in interaction is foregrounded in new and different ways from traditional desktop computing. Tangible technologies enable hands-on interaction with physical artefacts that can be used to digitally augment objects and interactions in flexible ways (Price et al., 2008). This has important implications in the context of learning, and scientific inquiry in particular, since it offers opportunities to create hands-on discovery learning environments that make visible invisible scientific phenomena through the digital augmentation of action with objects. For example, the LightTable described in this study essentially makes visible behaviours of light that cannot be seen by the human eye.

Central to interaction in these environments is the use of the hands in both manipulating objects and gesturing in various ways, yet we know little about the role that this plays in supporting scientific inquiry in digital learning contexts. While research in Human-Computer Interaction (HCI) has begun to explore the role of hand action in touch and tangible interfaces (e.g. Manches et al., 2010; Pontual Falcao and Price, 2011), none to date has closely examined its role in supporting learning, or scientific inquiry specifically. Roth (2002), on the other hand, has examined the role of hand action in supporting scientific inquiry, but in the context of traditional science experiments in classroom contexts. Digital technologies, such as tangibles, offer new ways for students to interact with scientific phenomena. In particular they can render scientific processes, such as light behavior, observable, not only in real time response to changes in object positioning in the light beam but also as static configurations on the table surface. This enables 'space' for reflection about scientific ideas (Ackerman, 1999). Tangible technologies are likely to change how hand actions are used to support scientific inquiry since the tangible environment involves interaction with both digital and physical information through the manipulation of physical objects, where both the physical properties of the objects and the properties of the digital representations are central to the scientific ideas being explored. In contrast, in an environment that is not digitally augmented, hand actions only act upon physical representations without linking to digital representations of invisible phenomena. A key question then is how tangible technologies influence the hand actions used by learners to support the process of scientific inquiry. 
This paper takes a multimodal approach to embodied forms of interaction and discourses of scientific investigation using an interactive tangible tabletop. In so doing it focuses on the semiotic resources that hands are implicated in, aiming to develop a stronger and more precise way to talk about hands and touch, which is central to interaction with tangible and touch interfaces. A 'taxonomy' of hand actions for scientific inquiry in tangible digital environments is proposed based upon literature and observational research on the role of hand action in learning. Through the systematic tracking and analysis of hand action in line with phases of scientific inquiry the paper extends previous research, notably Roth's concept of a 'developmental trajectory', and explores whether and how this model can be applied to different (digital) contexts of scientific inquiry. The paper shows how the 'taxonomy' of hand actions can be used to analyze the development of scientific inquiry in tangible digital environments. The paper concludes by presenting an alternative model through which to understand the semiotic role of the hands in scientific inquiry.

\section{Embodied interaction}

The concept of embodied interaction draws attention to the role of the body in learning and communication (Streeck et al., 2011; Goodwin, 2000). Theories of child development have long emphasized the extent to which bodily experience supports individuals in the construction of abstract knowledge (e.g. Bruner, 1966). In recent years, the semiotic work of various embodied modes (including gaze, gesture, body position and manipulation) has been explored in multimodal studies of learning (Manches \& Price, 2011). In HCI, value is increasingly placed on the role of bodily resources in the organization of activity with artifacts and technology (Dourish, 2001). In the context of scientific inquiry, it is suggested that the body has a distinct semiotic role in the process of learning and plays a part, unfulfilled by language, in the developments of students' ideas about the world around them (e.g. Roth, 2002; Radinsky et al., 2012). Collectively this suggests that understanding how embodied forms of interaction in digital environments can support learning is of central importance, and in particular the role of hand action in supporting scientific inquiry via tangible environments. 


\section{A multimodal approach to scientific inquiry}

Learning through inquiry has become an increasingly popular approach in science education (Hofstein \& Lunetta, 2004). Scientific inquiry involves various skills and activities, including observing, asking questions, gathering evidence, planning investigations, reflecting on evidence and reporting results. Multimodal approaches to inquiry draw attention to the wide range of communication means that individuals make use of when demonstrating these skills and enacting these activities, thereby challenging an analytical focus on spoken and written language. While many key texts in science education acknowledge the role of embodied interaction, 'talk is considered the central mode of communication of the science classroom' (Mortimer \& Scott, 2003, p. 22). Multimodality contests this and stresses the extent to which learning about science is a multimodal pursuit (Kress et al., 2001; Ogborn et al., 1996), involving visual and embodied modes of meaning making, as well as language. Indeed, according to this perspective, even when talk or writing are the dominant modes in a text or interaction, the meaning of language is strongly shaped by the multimodal ensemble it is embedded within.

Although studies of science learning have adopted different models of scientific inquiry (e.g. Ogborn et al., 1996; Price et al., 2003), this paper draws on Mortimer and Scott's (2003) conceptualization of scientific inquiry. This model is considered the most appropriate for this multimodal analysis, despite their own empirical focus on talk in the science classroom, as it is applicable to taking non-linguistic interaction as a starting point. In this respect, the model is different to those that focus on hypothesis generation and testing and tend to foreground linguistic events i.e. inquirers verbally stating what they think will happen (e.g. Price et al., 2003). Scott and Mortimer focus on and distinguish between three stages of scientific inquiry:

1. Description: providing an account of a phenomenon

2. Explanation: referring to a model or mechanism underlying a phenomenon

3. Generalization: providing an explanation independent of specific examples 
This idea of a shift from description to the development of explanations can be realized by analyzing talk alongside other indicative markers that relate to embodied modes (e.g. the demonstration with hands of a causal chain). In the example of scientific inquiry presented here, students investigated the way light interacts with objects of different colours, textures and shapes. Their investigations took place via the tangible tabletop environment of the LightTable and were intended to develop students' understanding of the way in which light propagates through space indefinitely, and how its contact with objects changes its direction and colour depending on the object properties (see Osborne et al., 1993). The design of the LightTable enables reflections within this line of inquiry because digital representations of the light involve a single light beam that clearly changes colour and direction as a result of contact with the objects on the table; these changes persist for as long as the objects are unmoved. This contrasts with what is observable of light in the natural world, where light does not appear as a single beam and changes in its colour and direction are not always observable to the naked eye. As a result, the LightTable may enhance the potential for student reflection and the construction of scientific explanations.

\section{The semiotic work of the hands}

The role of embodied action, gaze, body position and posture in science learning with digital technologies has been discussed elsewhere (Price \& Jewitt, 2013). This paper sets out to supplement that research by honing in on hand actions to develop a descriptive language for analyzing hand action in scientific inquiry. Of course, the hands do not work separately from other parts of the body, but in looking at them independently for analysis, a more detailed understanding of the semiotic resources they make available and the contribution they make to the learning process can be developed.

The decision to focus on a part of the body (the hands) rather than a particular mode (e.g. gesture) enables the analysis to interrogate the idea that there is a functional distinction between gesture and other types of hand action. As Jaworski and Thurlow (2009) suggest, a distinction between contact and non-contact movements is not a straightforward one to make. In Goodwin's (2003) taxonomy of gestures, this is 
recognized through his inclusion of transformative gestures, which act upon or change the physical environment. Looking at all types of hand action in a single context makes it possible to recognize if and when manipulation and gesture do the same, or different, semiotic work in scientific inquiry. Different types of hand action have been found to be useful in distinct phases of knowledge construction. For example, gesture has been conceptualized as providing a bridge between observable phenomena and abstract explanations of what is no longer visible (Vygotsky, 1978; Cook \& Goldin-Meadow, 2006).

In-depth observation studies, such as those conducted by Roth (2002) and Radinsky et al. (2012), have suggested that the hands are so central because they facilitate the assembly of representational fields that bridge observations of physical phenomena and abstract conceptualizations of these phenomena. Roth (2002) suggests a developmental trajectory of hand actions in scientific inquiry whereby initial explorations are supported by the manipulation of objects while explanations are facilitated by gesture. In this conceptualization of hand action, gesture has a particular place in the chain of scientific inquiry. It takes place after manipulation, but before linguistic explanations. In this paper we apply, critique and extend Roth's model by mapping hand action in relation to scientific inquiry.

\section{A taxonomy of hand actions for scientific inquiry}

In order to map the work of the hands against stages of scientific inquiry, we drew on the literature to construct a taxonomy of hand actions that may contribute towards inquiry in a distinct way. The taxonomy presented here is not an attempt to create a universal classification of hand action, but rather to explore how hand action features in science inquiry learning in digital environments such as the one used in this study. Various taxonomies of gesture and manipulation have been constructed in previous research (e.g. Kirsh \& Maglio, 1994; Jaworski \& Thurlow, 2009; Goodwin, 2003; Cook \& GoldinMeadow, 2006). The distinctions made by Roth (2002) were particularly relevant because of their application in contexts of scientific inquiry. Primarily, we used these distinctions and our initial observations of the video data in order to create the following taxonomy. 
In the taxonomy, both contact and non-contact hand actions are included, as are actions that rely on the external environment and those that do not. It should also be noted that this taxonomy does not include all possible categories of hand action. For example, 'beats' (see Krauss et al., 2000) have not been included since they are unlikely to relate to scientific inquiry in a specific way.

\section{Ergotic movements}

Ergotic movements are those that change the surrounding environment (Roth, 2002; in Goodwin, 2003, these are described as 'transformative gestures'). Such movements may involve changing the position of an object, or attempting to change its physical properties. In the context of scientific inquiry, ergotic movements are necessary in order to facilitate observations of particular phenomena. Manches and Price (2011) suggest that manipulation may be important as a result of the changes in representational state (digital and physical) that it facilitates, which in turn allow the development of new ideas. In the context of this analysis, for example (see figure 1), students needed to move the torch, or the objects, so that they interacted with the light beam on the tangible surface and elicited different digital effects relating to the reflection, refraction and absorption of light according to object colour, shape and texture.

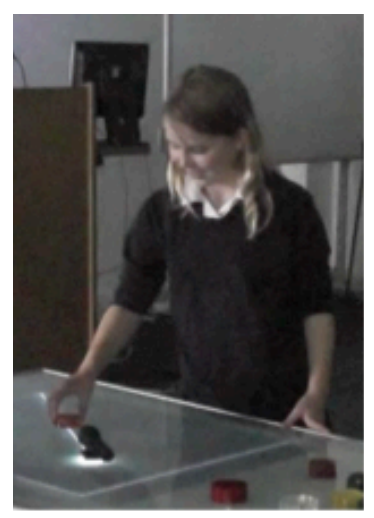

Figure 1. Ergotic movement: The student positions the object in the light beam in order to see what happens 


\section{Epistemic movements}

Epistemic movements are those that enable an individual to know more about the physical properties of an object (Roth, 2002). While ergotic movements are designed to change the surrounding environment, epistemic movements enable better perception of the surrounding environment through manipulation. In Kirsh and Maglio (1994), epistemic actions are conceptualized as those that uncover information that makes later mental computation simpler. In exploring the behavior of light, students often held or manipulated objects in order to learn more about the properties of an object, including its weight and texture (see figure 2).

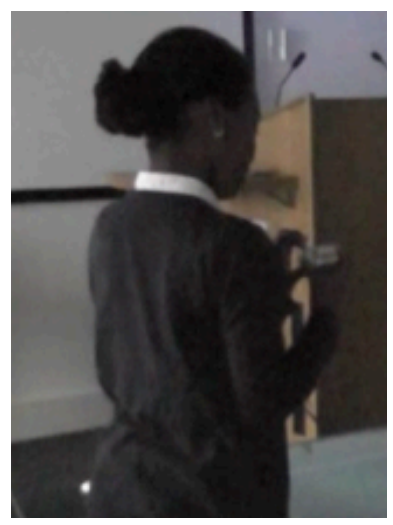

Figure 2. Epistemic movement: The student feels the object while holding it to explore its texture

\section{Deictic gesture}

Deictic gestures are used to point to or physically highlight objects or areas in the physical world. They may be used to draw attention to a representational field or a particular aspect within a field. Radinsky et al. (2002) describe how this gesture is used to shift attention between different sites of representation. In the study conducted here, students used deictic gesture to focus attention on the properties of a particular object, the digital effect or to widen their focus to reference other objects. For example, in order to compare the behavior of light in relation to two different objects, the students manipulated one object and pointed to the other (see figure 3). 


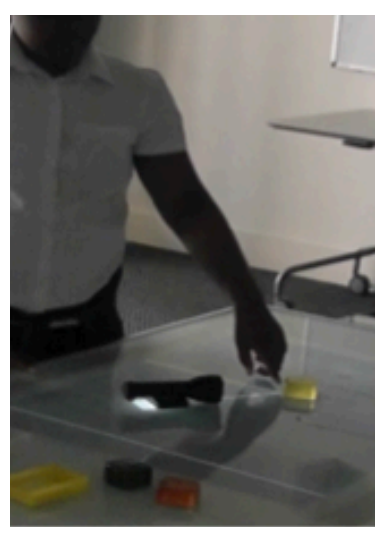

Figure 3. Deictic gesture: The student points at the object in order to draw attention to it.

\section{Re-enactment gestures}

Re-enactment gestures are used to slow down processes that are otherwise too fast to be visible (Roth, 2002). For example, Roth observed students using gestures to represent the movement of electrons. In the context of the tangible tabletop, digital effects that occur dynamically can also be viewed as a static configuration, enabling students to use reenactment gestures to trace how light was moving between different objects on the table surface (see figure 4), for example moving a fingertip along the table to represent the direction and length of the light beam. In a single moment, a re-enactment gesture may appear to be a deictic gesture, but over time the distinction is clear since re-enactment gestures involve tracing a process rather than referring to a single element of the environment.

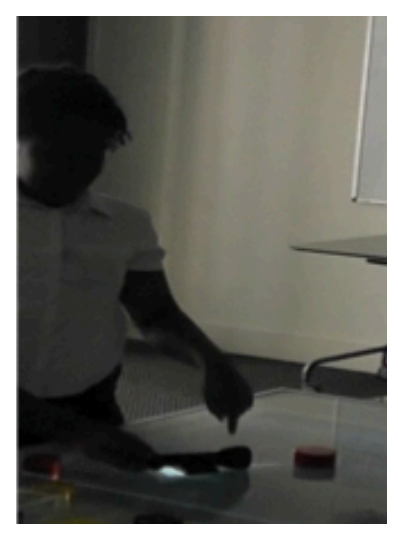

Figure 4. Re-enactment gesture: The student traces her fingertip along the table to demonstrate the behavior of the light. 


\section{Ideational gestures}

Ideational gestures (also called representational gestures, Jaworski \& Thurlow, 2009) are different to the other categories in this taxonomy because they introduce content that is not present in the external environment. They include iconic and metaphoric gestures, which exist on a spectrum of how direct the pictographic relationship between the gesture and the referent is. In the context of scientific inquiry, students may wish to invoke previously learned knowledge in order to make sense of what is currently occurring. Gesture may be helpful in this because it constitutes a way of representing absent knowledge. In the context examined in this paper, ideational gestures could be used to support the introduction of alternative references to the behavior of light. For example, gestures were used to demonstrate the refraction of light as it comes into contact with a window (see figure 5).

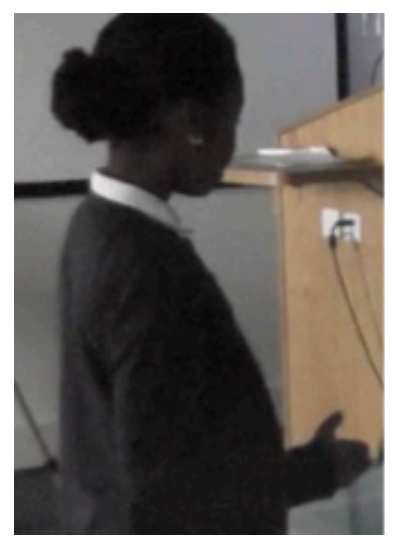

Figure 5. Ideational gesture: The student uses an ideational gesture to invoke prior experiences of light travelling through a window.

\section{Data and Method}

The questions underpinning this analysis were: 1) How do hand actions relate to different stages of scientific inquiry? 2) What work do the hands do within these stages of inquiry? In order to answer these questions, the actions of the hands were observed in a specific context of scientific inquiry, using the taxonomy of hand actions introduced above, as well as the stages of scientific inquiry described by Mortimer and Scott (2003). 
Participants, aged 10-11 years, were students at a London primary school. 10 pairs ( $\mathrm{F}=12$, $\mathrm{M}=8$ ); the teacher selected pairs on the basis that they would be able to work well together.

The LightTable, a tangible tabletop facilitating the scientific investigation of the behavior of light (see Figure 6), was set up in a large room within the university. Video cameras were positioned around the room and above the tabletop to record different views of participant interaction. Prior to interaction, students were given a brief introduction to scientific content that would be helpful in the tasks ahead. They were reminded that a white light beam comprises several colours and splits into these different colours when it is shone through a prism. This was relevant in understanding the behavior of light when it comes into contact with different coloured objects. Each pair of students then spent approximately 20 minutes interacting with the LightTable, undertaking three tasks to explore what happens to a white beam of light when it comes into contact with objects that have different physical properties. While each task was introduced by a brief explanation from one of the researchers, the students' scientific inquiries were not facilitated beyond this.

The LightTable consists of a table with a frosted glass surface, illuminated by infrared LEDs. A variety of plastic objects, each tagged with a 'fiducial' marker, are used as input devices. When placed on the surface, objects are tracked by an infrared camera and recognized by the computer system. As a result, they elicit programmed digital effects that are projected onto the table surface. This application was designed to illustrate how objects reflect, refract and absorb light, according to their physical properties (shape, material and colour). A torch acts as a light source eliciting a digital white light beam when placed on the table, and the objects elicit digital effects only when placed in a digital light beam pathway. Digital effects change when objects are directly manipulated, either by being taken off the table or altering their position, which causes the light beam to be interrupted or redirected. 

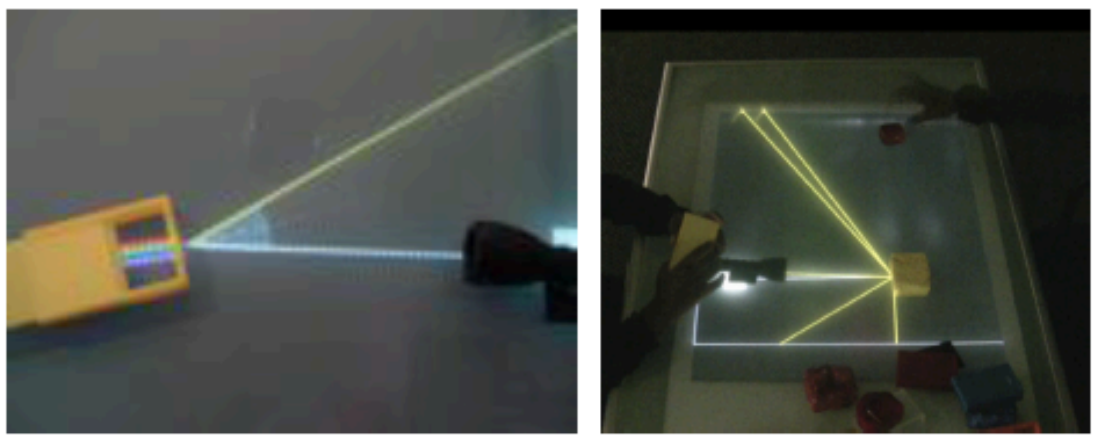

Figure 6. The LightTable and input devices

\section{Analysis}

The analysis aimed to explore the role of hand action in students' scientific inquiry while using the tangible environment described. Selected episodes of interaction were chosen because they constitute illustrative examples of what was seen across the large amount of video data that was collected. The two episodes presented here are typical in that the mappings they demonstrate between hand action and inquiry were seen in other parts of the video data. On the other hand, their diversity in comparison to each other enables us to challenge the claim that there is a developmental trajectory of hand action in the inquiry process.

Each episode comprises three consecutive frames of action, as this number of shifts in attention enabled us to observe students making comparisons between different objects, and therefore to observe the inquiry process developing. By witnessing three frames of action, a large range of hand actions could be witnessed. It was important to observe various hand actions in each episode, in order to understand what role these actions have in the process of scientific inquiry. Frames of action can be identified on the basis of shifts in communication (Scheflen, 1974; Kress et al., 2001). In the context we were exploring, frames of action were based on a change in the focus of attention. For example, a new frame of action was identified when the attention of the students shifted from the researcher to the tabletop, or from one object to another. The direction of 
attention could be assessed through the body position and gaze of the participants, as well as through the direction of their hand action i.e. whether they were touching or gesturing towards a particular object.

Once the episodes were identified, a detailed multimodal transcription of the episodes was completed, focusing on hand actions and accompanying talk. This comprised a parallel record for each student including: time stamps, descriptions of hand action, categorisation of hand action, and speech (see Table 1).

Hand actions were contextualized with reference to spoken language, as well as other modes that were accessed through the video data and not transcribed (e.g. gaze and body position). By considering the multimodal ensemble of activity, it was possible to assess what stage of the scientific inquiry process the students were in (description, explanation, or generalization). Coding these stages was achieved with reference to Mortimer and Scott's definitions of each stage. All authors on this paper coded the stages (and accompanying hand actions) separately and compared their coding in order to check that there was general agreement in the application of codes.

\section{Findings}

In the following two episodes, the actions of the hands are outlined in relation to the inquiry process students are engaged in. These actions are then considered in terms of the contribution they make towards the inquiry process. An overview of each episode is first presented. This is followed by a more detailed focus on the frames included in the episode. Each frame is described in a vignette, and hand actions are then mapped to the stages of scientific inquiry in a subsequent table.

The episodes described below support the theory that the hands do distinct semiotic work in the process of scientific inquiry. What the hands are doing can be linked to different stages of scientific inquiry: the hands can facilitate description, explanation and generalization. On the other hand, the relationship between hand actions and stages of scientific inquiry was not consistent. A wide variety of hand actions could be used in 
relation to each stage. Thus, while the hands do important semiotic work in scientific inquiry, they cannot be mapped rigidly according to stages of scientific inquiry.

Episode 1 (Pair A, 1:34-3:10)

In this episode, one female student and one male student are positioned on the same side of the tabletop. They collaborate closely in order to test the behavior of light in relation to three different objects. They are methodical in their use of the objects, and return each object to the inactive part of the tabletop before they begin exploration with another object. The episode begins following a brief introduction to the task by the researcher. During the first frame of action, the students explore the coloured refraction of the light beam that occurs as a result of its contact with a yellow cylindrical object. After observing this, they return the object to the inactive part of the tabletop. The second frame of action begins when they place a transparent cylindrical object onto the tabletop, and explore the refraction of light by this object. It ends when they return this object to the inactive part of the tabletop. The final frame of action begins when one student picks up a red cuboid to compare its properties with those of the transparent cylinder that remains on the tangible tabletop. The frame of action (and episode) ends when both objects are returned to the inactive part of the tabletop.

The events in this episode both support and challenge Roth's (2002) developmental trajectory of hand action in inquiry. As suggested by Roth, both ergotic and epistemic movements are used to facilitate the description of scientific processes. Deictic gestures are used to draw attention to relevant properties of the phenomena (e.g. the shape of the object and the colour of the light beam) and re-enactment gestures are used as a demonstration tool when the students try out explanations on one another. On the other hand, the students do not use ideational gestures in order to invoke alternative sites of representation or prior knowledge. Instead, they widen the site of interest and facilitate explanation by using ergotic movements to compare objects and epistemic movements to identify the properties of these objects that are relevant to the behavior of light. The plurality of hand actions that supported explanation in this episode is shown in Figure 7. 


\begin{tabular}{|l|l|l|}
\hline $\begin{array}{l}\text { Re-enactment gestures } \\
\text { support demonstration }\end{array}$ & $\begin{array}{l}\text { Deictic gestures focus } \\
\text { attention on causal properties }\end{array}$ & $\begin{array}{l}\text { Epistemic movements facilitate } \\
\text { comparisons of causal } \\
\text { properties }\end{array}$ \\
\hline $\begin{array}{l}\text { 'The light goes through and } \\
\text { hits there...' }\end{array}$ & 'Because of the colour...' & $\begin{array}{l}\text { 'Because there are no edges } \\
\text { like how you have on this one.' }\end{array}$ \\
\hline
\end{tabular}

Figure 7. Explanation is supported by a range of hand actions, including deictic gesture and epistemic movements.

\section{Frame 1 (1:34 - 2:28; see Table 2)}

A yellow cylindrical object has been placed on the tangible tabletop so that it is contact with the light beam from the torch. One student comments 'here the light bounces off and reflects', while pointing at the light on the tabletop to focus attention on the site of activity. Gestural re-enactment is used to slow down the observed process of refraction. One student describes how 'the light goes' by tracing the light beam on the table surface with her finger. The other student responds by suggesting that the colour of the object might be important. He draws attention to the object properties by pointing at the object and then at the light beam. These deictic gestures suggest a causal link between the object properties and the behavior of the light, and therefore have explanatory power. This is supported by what he says as he makes these gestures: 'it's going to be the same colour as the light'. The first student continues to verbally describe the movement of the light: 'it reflects and the reflection is shown' while tracing the light with a fingertip.

Table 2. Episode 1, Frame 1 


\begin{tabular}{|c|c|c|c|}
\hline $\begin{array}{l}\text { Episode } 1 \\
\text { Frame } 1\end{array}$ & Activity & Hand Action & $\begin{array}{l}\text { Development of } \\
\text { Scientific Inquiry }\end{array}$ \\
\hline $1: 34$ & $\begin{array}{l}\text { Student A points at the } \\
\text { object on the tabletop. }\end{array}$ & Deictic gesture & \\
\hline $1: 37$ & $\begin{array}{l}\text { Student A moves the object } \\
\text { so that it is in contact with } \\
\text { the light beam. }\end{array}$ & Ergotic movement & \\
\hline $1: 45$ & $\begin{array}{l}\text { Student A traces the } \\
\text { movement of light across the } \\
\text { tabletop. }\end{array}$ & $\begin{array}{l}\text { Re-enactment } \\
\text { gesture }\end{array}$ & \\
\hline $1: 56$ & $\begin{array}{l}\text { Student B points at the } \\
\text { object. }\end{array}$ & Deictic gesture & $\begin{array}{l}\text { Connecting the } \\
\text { colour of the object } \\
\text { to the colour of the } \\
\text { reflected light. }\end{array}$ \\
\hline 2:02 & $\begin{array}{l}\text { Student B points at the light } \\
\text { beam. }\end{array}$ & Deictic gesture & \\
\hline $2: 11$ & $\begin{array}{l}\text { Student A traces the } \\
\text { movement of the light with } \\
\text { her fingertips. }\end{array}$ & $\begin{array}{l}\text { Re-enactment } \\
\text { gesture }\end{array}$ & \\
\hline
\end{tabular}

Frame 2 (2:28-2:48; see Table 3)

To develop their observations, the students place a transparent cylindrical object onto the tabletop. The students use ergotic movements and deictic gestures to draw attention to the properties of the new object that might be relevant to the behavior of light e.g. that the object is a cylinder.

Table 3. Episode 1, Frame 2 


\begin{tabular}{|l|l|l|l|}
\hline $\begin{array}{l}\text { Episode 1 } \\
\text { Frame 2 }\end{array}$ & Activity & Hand Action & $\begin{array}{l}\text { Development of } \\
\text { Scientific Inquiry }\end{array}$ \\
\hline $2: 28$ & $\begin{array}{l}\text { Student A places a } \\
\text { transparent cylindrical object } \\
\text { onto the tangible tabletop. }\end{array}$ & Ergotic movement & Student A manipulates the \\
object. & $\begin{array}{l}\text { Ergotic movement } \\
\text { Student A points at the torch. }\end{array}$ & Deictic gesture & $\begin{array}{l}\text { Connecting the } \\
\text { shape of the object } \\
\text { to the behavior of } \\
\text { the light. }\end{array}$ \\
\hline
\end{tabular}

Frame 3 (2:48-3:10; see Table 4)

In order to highlight how differences in shape might be relevant to the behavior of light, the student described in the frame above picks up a red cuboid. She verbally explains that this object has vertices and uses her fingertip to demonstrate what these are to the other student. While this action is not a gestural movement, it widens the site of activity that the students are engaged in and enables them to explain, rather than just describe, the behaviours they are observing. The student continues to develop her explanation of why this would affect the behavior of the light: 'it can't really go round - it's just straight'. She supports this assertion by tracing the light beam with her fingertips on the table surface. Both objects are then returned to the inactive part of the tabletop.

Table 4. Episode 1, Frame 3

\begin{tabular}{|l|l|l|l|}
\hline $\begin{array}{l}\text { Episode } 1 \\
\text { Frame } 3\end{array}$ & Activity & Hand Action & $\begin{array}{l}\text { Development of } \\
\text { Scientific Inquiry }\end{array}$ \\
\hline $2: 48$ & $\begin{array}{l}\text { Student A picks up a red } \\
\text { cuboid. }\end{array}$ & Ergotic movement & \\
\hline
\end{tabular}




\begin{tabular}{|l|l|l|l|}
\hline $2: 50$ & $\begin{array}{l}\text { Student A feels the vertices } \\
\text { of the cuboid with her } \\
\text { fingertip, drawing attention } \\
\text { to the shape. }\end{array}$ & $\begin{array}{l}\text { Epistemic } \\
\text { movement }\end{array}$ & $\begin{array}{l}\text { Connecting the } \\
\text { shape of the object } \\
\text { to the behavior of } \\
\text { the light. }\end{array}$ \\
$2: 55$ & $\begin{array}{l}\text { Student A traces the light } \\
\text { beam with her fingertip. }\end{array}$ & Deictic gesture & \\
\hline
\end{tabular}

Episode 2 (Pair B, 15:53 - 17:07)

In this episode, two male students are positioned on opposite sides of the tabletop. They are often engaged in different lines of inquiry and do not prioritize collaboration with one another. They are not methodical in their observations of different objects, and a large number of objects are placed on the tabletop. In this episode, however, they both focus their attention on two particular objects; a yellow rough-edged object and a blue roughedged object. The episode begins following a brief introduction to the task by the researcher, and the introduction of some new objects placed onto the inactive part of the tabletop. The first frame of action begins when one student places a blue rough-edged object onto the tabletop and exclaims over the effect that is created. The second frame of action begins when the other student places a yellow rough-edged object in between the blue rough-edged object and the source of the light beam. The final frame of action begins when this student draws attention back to the blue rough-edged object by picking it up and considering what kind of material it is and what effect this has on the light beam. The episode ends when all of the objects that are on the tabletop are pushed onto the inactive part of the tabletop.

As with the first episode, the development of explanations is supported by a range of different hand actions (see Figure 8). This challenges Roth's notion of a developmental trajectory of hand action. Furthermore, the first frame of action demonstrates that 
ideational gestures do not necessarily support the development of explanations; they can be present in simple descriptions of phenomena also.

\begin{tabular}{|l|l|l|}
\hline $\begin{array}{l}\text { Re-enactment gestures support } \\
\text { demonstration }\end{array}$ & $\begin{array}{l}\text { Epistemic movements support } \\
\text { investigation of causal } \\
\text { properties }\end{array}$ & $\begin{array}{l}\text { Ergotic movements enable } \\
\text { comparison of objects with } \\
\text { similar properties }\end{array}$ \\
\hline & & $\begin{array}{l}\text { 'It's got } \\
\text { like...erm...cardboard. } \\
\text { What's this called?' }\end{array}$ \\
\hline $\begin{array}{l}\text { 'I think this one goes there and } \\
\text { then spreads around.' }\end{array}$ & it.' \\
\hline
\end{tabular}

Figure 8. Explanation is supported by a range of hand actions including ergotic and epistemic movements.

Frame 1 (15:53 - 16:04; see Table 5)

One of the students places the blue rough-edged object onto the tangible tabletop in contact with the light beam. As a result, the light is reflected in multiple beams scattered in different directions. The other student exclaims 'oh my goodness, it's a disco!' A few seconds later, he uses hand gestures to suggest that he is dancing. By doing this, the student is using gesture to invoke an alternative representational site that is relevant because of the effect being observed. It draws attention to the perception of multiple light reflections but it does not facilitate an explanation of phenomena because the example invoked by the student does not relate to the mechanisms at work in the example under current examination.

Table 5. Episode 2, Frame 1 


\begin{tabular}{|l|l|l|l|}
\hline $\begin{array}{l}\text { Episode 2 } \\
\text { Frame 1 }\end{array}$ & Activity & Hand Action & $\begin{array}{l}\text { Development of } \\
\text { Scientific Inquiry }\end{array}$ \\
\hline $15: 53$ & $\begin{array}{l}\text { Student B places the blue } \\
\text { rough-edged polystyrene } \\
\text { object onto the tangible } \\
\text { tabletop in contact with the } \\
\text { light beam from the torch. }\end{array}$ & Ergotic movement & \\
$15: 58$ & $\begin{array}{l}\text { Student B manipulates } \\
\text { objects on the tabletop. }\end{array}$ & Ergotic movement & \\
16:03 & $\begin{array}{l}\text { Student B uses his hands to } \\
\text { suggest that he is dancing. }\end{array}$ & Ideational gesture & \\
\hline
\end{tabular}

Frame 2 (16:04 - 16:30; see Table 6)

The other student places a yellow rough-edged object in between the light source and the blue rough-edged object. After manipulation, he says 'I think the torch goes there'. As he verbally describes the light, his hands re-enact the process through gesture, slowing the observed process down. He begins to link the behavior of the light to the texture of the object. He says 'the light spreads around because...' and then he hesitates trying to find a word to describe the texture of the object he is holding. He draws attention to the texture by tapping the object, and turning it around in his hands. These are epistemic movements designed to find out more about the object and prompt recall of the words that could be used to describe the material of the object.

Table 6. Episode 2, Frame 2

\begin{tabular}{|l|l|l|l|}
\hline $\begin{array}{l}\text { Episode 2 } \\
\text { Frame 2 }\end{array}$ & Activity & Hand Action & $\begin{array}{l}\text { Development in } \\
\text { Scientific Inquiry }\end{array}$ \\
\hline
\end{tabular}




\begin{tabular}{|c|c|c|c|}
\hline $16: 04$ & $\begin{array}{l}\text { Student A places a yellow } \\
\text { rough-edged object onto the } \\
\text { tangible tabletop, in between } \\
\text { the light source and the blue } \\
\text { rough edged object. }\end{array}$ & Ergotic movement & \\
\hline $16: 07$ & $\begin{array}{l}\text { Student A manipulates the } \\
\text { object. }\end{array}$ & Ergotic movement & \\
\hline $16: 17$ & $\begin{array}{l}\text { Student A uses his hands to } \\
\text { show how the light is } \\
\text { moving. }\end{array}$ & $\begin{array}{l}\text { Re-enactment } \\
\text { gesture }\end{array}$ & \\
\hline $16: 21$ & $\begin{array}{l}\text { Student A picks up and feels } \\
\text { the object, drawing attention } \\
\text { to its texture. }\end{array}$ & $\begin{array}{l}\text { Epistemic } \\
\text { movement }\end{array}$ & $\begin{array}{l}\text { Connecting the } \\
\text { texture of the object } \\
\text { to the behavior of } \\
\text { the light. }\end{array}$ \\
\hline
\end{tabular}

Frame 3 (16:30 - 17:07; see Table 7)

In order to consider the importance of material further, the student returns attention to the blue rough-edged object, which he picks up. He tries to remember what the material is called and eventually asks the researcher. His attention moves between the properties of the object, which are explored through epistemic movements, and the behavior of the light, which is re-enacted through gesture. His hand movements indicate that he is making a causal link between the material of the object and the behavior of the light. This is supported by his verbal explanation: 'because it's got little dots... and it goes, spreads it around'.

Table 7. Episode 2, Frame 3 


\begin{tabular}{|l|l|l|l|}
\hline $\begin{array}{l}\text { Episode 2 } \\
\text { Frame } 3\end{array}$ & Activity & Hand Action & $\begin{array}{l}\text { Development in } \\
\text { Scientific Inquiry }\end{array}$ \\
\hline $16: 30$ & $\begin{array}{l}\text { Student A picks up the blue } \\
\text { polystyrene object and feels } \\
\text { it with his fingertips } \\
\text { repeatedly. }\end{array}$ & $\begin{array}{l}\text { Epistemic } \\
\text { movements }\end{array}$ & $\begin{array}{l}\text { Connecting the } \\
\text { texture of the object } \\
\text { to the behavior of } \\
\text { the light. }\end{array}$ \\
$16: 40$ & $\begin{array}{l}\text { Student A uses gesture to } \\
\text { show the movement of the } \\
\text { light. }\end{array}$ & $\begin{array}{l}\text { Re-enactment } \\
\text { gesture }\end{array}$ & \\
\hline
\end{tabular}

\section{Discussion}

An in-depth analysis of the video data collected made it clear that the hands do important semiotic work in the context of scientific inquiry. On the basis of Roth's developmental trajectory of hand actions, it was expected that students' descriptions of scientific phenomena would be supported by the manipulation of objects and their explanations would be supported by gestural movements. This hypothesis was not supported by the data here, which suggest that the role of the hands in scientific inquiry is more complex than Roth's trajectory indicates. Mapping the action of the hands in this context of scientific inquiry demonstrated that, as Roth predicted, the progress from description to explanation was sometimes supported by gesture. The data showed however, that manipulation - ergotic and epistemic movements - could also be involved in the construction of scientific explanations. A different model is therefore needed to account for the semiotic role of the hands in scientific inquiry.

A new model of hand actions in scientific inquiry needs to account for a range of links that exist between what the hands are doing and how inquiry is progressing. These links were present in the video data analysed. Ergotic and epistemic movements were used to facilitate observations of phenomena, make comparisons and demonstrate important phenomena to others. Deictic and re-enactment gestures were used to draw attention towards particular aspects of the phenomena being observed and make causal links between them. Ideational gestures played a role in invoking prior experiences of the 
behavior of light, for example likening the reflection of light from a rough edged object to the light effects in a disco. While this example did not help to uncover the mechanisms underlying this type of light behavior, other episodes (not reported here) included the use of ideational gestures that did help to construct a deeper understanding of the phenomena being observed. All of these hand actions can be thought of as either narrowing the focus of inquiry so that it rests on a single feature of the immediate and visible phenomena, or widening the focus to encompass other parts of reality, so that explanations of the phenomena and generalisations can be developed. In widening the focus, the hands facilitated comparisons between objects or processes, rendered the temporal dimensions of a process visible, or linked current observations with prior knowledge or experience. Widening the focus was achieved through a range of hand actions, both contact and gestural actions.

By concentrating on the hands, a different model of scientific inquiry has emerged - one that is better able to take into account the wide variety of modes that are involved in the inquiry process. Instead of using the categories of Mortimer and Scott (2003; description, explanation and generalization) that were developed with reference to talk in the science classroom, our findings suggests that inquiry can be thought about as a series of activities that widen the site of interest. Inquiry begins with a focus on a specific phenomenon, and subsequently draws in relevant comparisons and knowledge, before panning out to construct explanations of phenomena that are independent of specific examples. By thinking about inquiry in this way, it is possible to consider equally the contribution made by different modes. Hand actions play a vital role in widening the site of interest. Gaze, talk and body positioning could all be understood in a similar way, and over the course of the inquiry process, would be seen to play a role in widening the site of interest.

Although our findings demonstrate that the hands do important semiotic work in the context of scientific inquiry, they also show that these contributions cannot be rigidly mapped. There needs to be a flexible approach taken towards 'reading' the work of the hands. Manipulation and gesture will not always be used in the same way and for the same purposes. Methodologically, this finding reiterates the importance of seeing communication as a multimodal ensemble of activity, in which various modes exist in 
relation to one another (Goodwin, 2000). While we might separate the mode of gesture from the mode of manipulation, they sometimes do the same work in the context of inquiry. Furthermore, some hand actions are not easily defined as either manipulation or gesture. Using the hands as a starting point for analysis provides a way around these problems but leads to other issues, such as the false separation between what the hands are doing and other aspects of body movement and positioning.

The findings from this study are important in the future design of tangible technologies to support scientific inquiry. Embodied action can only be understood in relation to the wider physical environment in which it occurs (Jaworski \& Thurlow, 2009). The work of the hands is embedded in the materialities of the space in which action takes place, as well as in the way that this space is socially constructed by actors within it. The tangible tabletop used in this study enabled representations of light behavior to remain static in a way that is often not possible. Within the environment offered by the tabletop, digital representations of light involved a single beam that was changed in a clearly visible way as a result of its contact with objects on the tabletop. As a result, students using the table could withdraw from physical manipulation while the representation created by the manipulation persisted. For example, once the students directed the light beam towards an object, they could let go of the objects involved and the effect would continue to be visible. If scientific inquiry is enabled through a widening of the site of interest, allowing representations to persist beyond the moment of their creation will better enable students to make comparisons, investigate the temporal dimension of activity and invoke relevant prior knowledge. Digital environments can therefore play a role in facilitating the use of a wide range of hand actions to support the inquiry process, in a manner that is not possible when events and representations are transient and constant manipulations are necessary in order for effects to persist. Previous research has suggested that by focusing on the physical manipulation of objects, students are less able to attend to abstract concepts because they cannot attend to both at the same time (Uttal et al., 1997). Thus, by making it possible to withdraw from manipulation while the representation created by the manipulation persists, tangible technologies such as the LightTable may help to prevent students from becoming overwhelmed by transient 
information, common in dynamic digital visualisations, and thereby facilitate abstract conceptualisations of the visible phenomena.

Another important finding from a design perspective was that students were observed using gestural re-enactment in order to slow down scientific processes that they were observing and to make the temporal dimension of a process more salient. By tracing the movement of light through space, students drew attention to the way light propagates through space indefinitely until coming into contact with objects that change its behavior. This is a key feature of light that is often not recognized by young students of science (Osborne et al., 1993). In future tangible tabletop environments, is there an opportunity to make this temporal dimension even more salient by showing the process in action? For example, in investigating light behaviours, the projection of light could be shown in slow motion moving from the source of the light to the object and then being refracted. Once this process had been shown over a few seconds, the representation could then remain static. Furthermore, enabling students to observe scientific processes as they unfold may also give students an opportunity to plan their subsequent activity, for example, identifying which object they would like to test on the tabletop next. Manches and Price (2011) highlight the need to find a balance between learning environments that facilitate actions, while at the same time hindering rapid action in order to foster planning behaviours.

\section{Conclusions}

In-depth analysis of pairs of students doing scientific inquiry into the behavior of light showed that the hands do important semiotic work in the context of inquiry. While this work cannot be rigidly mapped and has to be understood as just one part in a multimodal ensemble of activity, the hands played an important role in inquiry. Students' scientific inquiry has most often been thought and talked about in linguistic terms. By conceptualizing inquiry through physical action as the widening of a site of interest, we are accepting the potential of various modes to contribute to this process and are therefore broadening the discourse that surrounds science learning. The research we have conducted problematizes the way in which semiotic resources have been categorized in 
the past. While studies of human movement have tended to distinguish between contact and non-contact movement, our findings suggest that such a distinction does not relate to a clear divide in function. Gesture and manipulation, though distinct modes, are intertwined and can be used to achieve similar purposes. The semiotic work of the hands in scientific inquiry comes about as a result of interaction with the surrounding environment, both its physical and digital materialities and the way it is constructed by those present in it. As a result, looking at what the hands are doing can help us to identify aspects of the learning environment that can be improved. For example, the use of reenactment gestures by students in order to 'slow down' observed scientific processes, suggests that projections of stimuli in tangible tabletop environments could have an added temporal dimension that helps students to understand the processes that are occurring.

\section{References}

Ackerman, E. (1999) Enactive Representations in Learning: Pretense, Models, and Machines. In Bliss, J., Light, P. and Saljo, R. eds. Learning Sites: Social and technological Contexts for learning, Elsevier, 144-154

Bruner, J. S. (1966) Toward a theory of instruction. Cambridge, MA: Harvard University Press.

Cook, S. W., \& Goldin-Meadow, S. (2006) The role of gesture in learning: Do students use their hands to change their minds? Journal of Cognition and Development, $7(2), 211-232$.

Dourish, P. (2001) Where the Action Is: The Foundation of Embodied Interaction. Cambridge, MA: MIT Press.

Goodwin, C. (2000) Action and embodiment within situated human interaction. Journal of Pragmatics, 32, 1489 - 1522.

Goodwin, C. (2003) Pointing as situated practice. In S. Kita (ed.) Pointing: Where Language, Culture and Cognition Meet. Mahwah, NJ: Lawrence Erlbaum, 217 241.

Hofstein, A. \& Lunetta, V. N. (2004) The laboratory in science education: Foundation for 
the twenty-first century. Science Education, 88 (1), 28 - 54.

Jaworski, A. \& Thurlow, C. (2009) Gesture and movement in tourist spaces. In C. Jewitt (ed.) The Routledge Handbook of Multimodal Analysis. Abingdon: Routledge, $253-263$.

Kirsh, D., \& Maglio, P. (1994) On distinguishing epistemic from pragmatic action. Cognitive science, 18(4), 513-549.

Krauss, R. M., Chen, Y., Gottesman, R. F. (2000) Lexical gestures and lexical access. A process model. In D. McNeill (Ed.) Gesture and Language. Cambridge: Cambridge University Press, $261-283$.

Kress, G., Jewitt, C., Ogborn, J. \& Tsatsarelis, C. (2001) Multimodal Teaching and Learning: The Rhetorics of the Science Classroom. London: Continuum.

Manches, A., O'Malley, Claire, \& Benford, Steve. (2010). The role of physical representations in solving number problems: A comparison of young students's use of physical and virtual materials. Computers \& Education, 54(3), 622-640.

Manches, A., \& Price, S. (2011, June). Designing learning representations around physical manipulation: hands and objects. In Proceedings of the 10th International Conference on Interaction Design and Students (81-89). ACM.

Mortimer, E. F. \& Scott, P. H. (2003) Meaning Making in Secondary Science Classrooms. Maidenhead: Open University Press.

Ogborn, J., Kress, G., Martins, I. \& McGillicuddy, K. (1996) Explaining Science in the Classroom. Buckingham: Open University Press.

Osborne, J. F., Black, P., Meadows, J. \& Smith, M. (1993) Young children's (7-11) ideas about light and their development. International Journal of Science Education, 15 (1), 83-93.

Pontual Falcao, T. \& Price, S (2011). Interfering and resolving: How tabletop interaction facilitates co-construction of argumentative knowledge. International Journal of Computer-Supported Collaborative Learning Springer New York, Pages: 539-559

Price, S., Sheridan, J., Pontual Falcao, T. and Roussos, G. (2008). Towards a framework for investigating tangible environments for learning. International Journal of Arts and Technology: Special Issue on Tangible and Embedded Computing. Vol.1, Nos. 3/4, 351-368 
Price, S. \& Jewitt, C. (2013) A multimodal approach to examining 'embodiment' in tangible learning environments. Proceedings of the Seventh International Conference on Tangible, Embedded and Embodied Interaction. ACM.

Price, S., Rogers, Y., Stanton, D. \& Smith, H. (2003) A new conceptual framework for CSCL: Supporting diverse forms of reflection through multiple interactions. CSCL Conference 2003.

Radinsky, J., Ping, R., Hospelhorn, E. \& Goldman, S. (2012) Making the absent present: Emergent representational fields in students' negotiations of meaning with spatial data. AERA 2012.

Roth, W. M. (2002) From action to discourse: The bridging function of gestures. Cognitive Systems Research, 3(3), 535-554.

Scheflen, A. (1974) How Behaviour Means. New York: Jason Aronson.

Streeck, J., Goodwin, C. \& LeBaron, C. (2011) Embodied Interaction: Language and Body in the Material World. New York: Cambridge University Press.

Uttal, D. H., Scudder, K. V. \& DeLoache, J. S. (1997) Manipulatives as symbols: A new perspective on the use of concrete objects to teach mathematics. Journal of Applied Developmental Psychology, 18 (1), 37-54.

Vygotsky, L. (1978) Mind in Society: The development of higher psychological processes. Cambridge, MA: Harvard University Press. 